\title{
REAL OPTIONS USED IN NATURAL RESOURCE INVESTMENTS
}

\author{
KREMLJAK, Z.
}

Abstract:Research work of Black, Scholes and Merton in 1973 brought to a method, which enabled appropriate evaluation of options in the circumstances of uncertainty. This resulted in great increase of research in the field of evaluating financial assets. A possibility of evaluating so called financial options was not interesting only to academics but was also accepted in the field of business systems. This is a survey of basic terms and logic for evaluating financial options.The article express the usefulness of the real options theory by giving example in natural resource investment, namely when to stop a project, when to continue and when to finish it.

Key words: real options, call option, put option, financial option, case
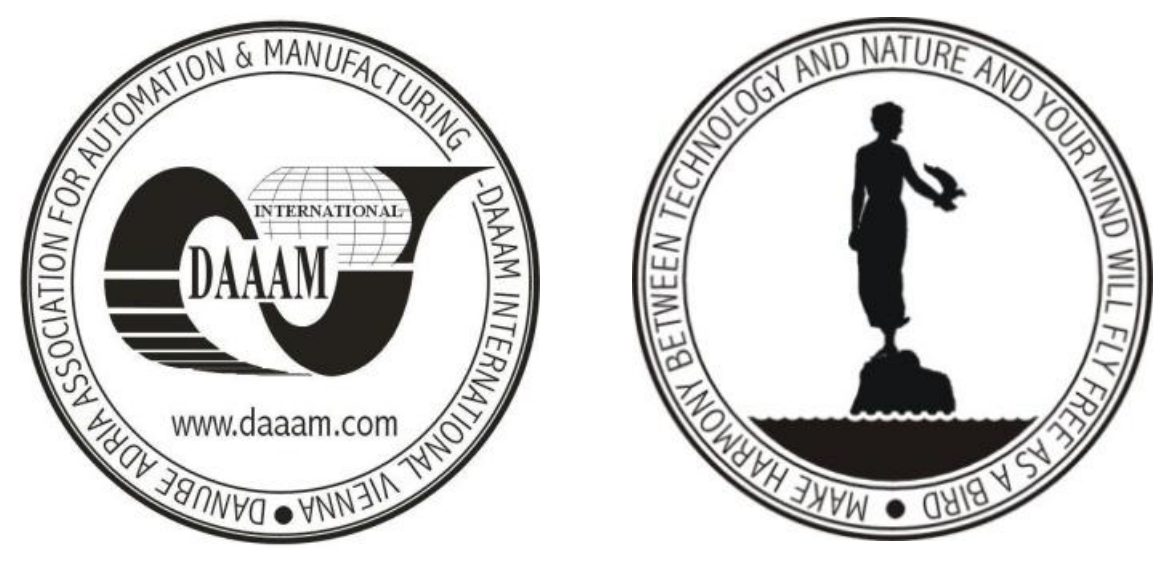

Authors' data: Dr. Sc. Kremljak, Z[vonko], Ministry of the Economy, Kotnikova 5, SI - 1000 Ljubljana, Slovenia, zvonko.kremljak@s5.net

This Publication has to be referred as: Kremljak, Z[vonko] (2010). Real Options Used in Natural Resource Investment, Chapter 10 in DAAAM International Scientific Book 2010, pp. 089-098, B. Katalinic (Ed.), Published by DAAAM International, ISBN 978-3-901509-74-2, ISSN 1726-9687, Vienna, Austria

DOI: $10.2507 /$ daaam.scibook.2010.10 


\section{Introduction}

Financial option is usually defined as the right to purchase or sell certain securities, for a price set beforehand and in a contractually specified deadline. In the context of options as financial tools, an option represents an agreement between two parties where the holder of the option has a right, which is not binding, to buy or sell under specified conditions. There are two basic types of options: call options and put options. A call option gives the holder the right to buy stock at a given price before or at a specified date (Trigeorgis, 2002). The price, for which the stock can be purchased, is called exercise price $(X)$. In advance set final time for exercising of option is called expiration date $(T)$. European type of call option allows purchase of securities on a specific expiration date, while American call option allows purchase at any given moment up to the specified expiration date. Buying stock represents an exercise of option. The buyer of a call option has to pay for the right to buy. The amount of payment is called price or value of call option $(C)$.

The value of call option $(C)$ represents the difference between the exercise price and current price of the stock. The value of call option can be graphically presented as the function of stock price $\left(S^{*}\right)$ (Figure 1).
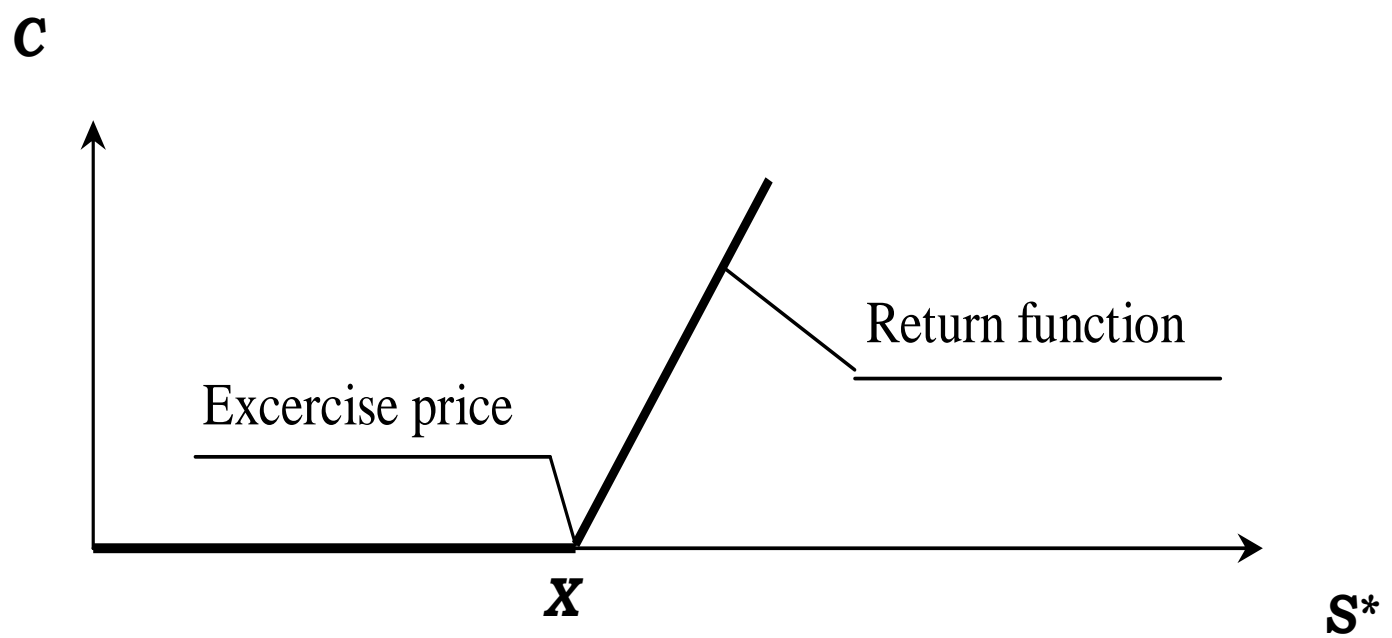

Fig. 1. The value of call option

The buyer of call option for stock will have profit in the event that the stock price in the future grows. In the event that the price of the stock falls, the option holder will not exercise it, which means that he will not suffer loss, barring transaction costs. Because of this the value of call option cannot be negative. One can presume that the current market price of stock with exercise price is $(X),\left(S^{*}\right)$. The value of call option $(C)$ is presented by the following equation:

$$
C=\operatorname{Max}\left[0, \mathrm{~S}^{*}-\mathrm{X}\right]
$$

Similarly, the put option $(P)$ presents the right to sell stock at given price before or after the specified date (Trigeorgis, 2002). Graphically, the value of put option can be presented as shown in Figure 2. 


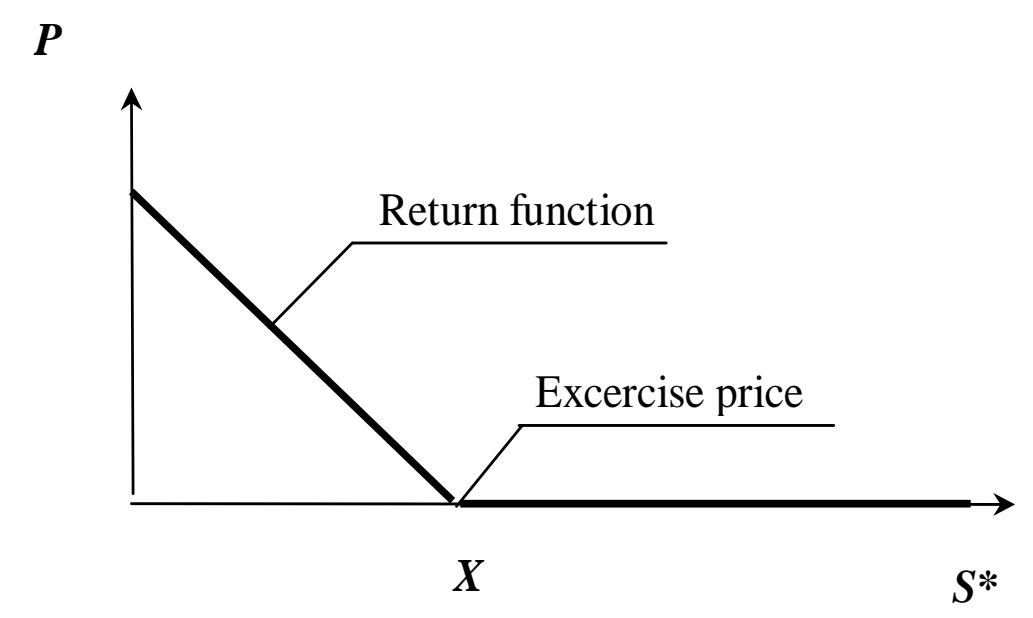

Fig. 2. The value of put option

In call as well as in put options we differentiate between American and European types. American type of put option allows the sale of security at any time until expiration date, while European type of put option can be executed only on the expiration date. The holder of put option will have profit from exercise price in the event that the stock price $\left(S^{*}\right)$ falls under the exercise price $(X)$. The value of put option is shown in the equation below.

$$
P=\operatorname{Max}\left[0, \mathrm{~K}-\mathrm{S}^{*}\right]
$$

The diagram in Figure 2 shows that theoretical value of put option lowers by increase in the stock price and reaches the value zero (0) when the price of stock is equal to exercise price.

As mentioned before, in 1973 Fish Black and Myron Scholes formulated first successful model for evaluating financial options, which is now known as BlackScholes model (Howell et al., 2001). To make the model functional they accepted the following premises and limitations:

- there is no payment of dividends,

- interest rate is known and constant,

- there are no transaction costs,

- option can be realised only on expiration date (European type),

- stock prices follow stochastic diffusion process and cannot take negative values.

The calculated optional value is a function of five variables:

- current stock price $S$,

- exercise price $X$,

- time to expiration date $T$,

- annual interest rate for risk less investment,

- variances of price fluctuations of stock $X$.

The model is useful for both call and put options. Thus the following function can be written $C=\mathrm{f}\left(S, X, T, r, \sigma^{2}\right)$. Value of put option $(C)$ is given with the following equation: 


$$
C=S \cdot N\left(d_{1}\right)-\frac{X}{e^{r(T-t)}} \cdot N\left(d_{2}\right)
$$

Where

$$
\begin{gathered}
d_{1}=\frac{\ln \left(\frac{S}{X}\right)+\left(r+\frac{\sigma^{2}}{2}\right) \cdot(T-t)}{\sigma \sqrt{T-t}} \\
d_{2}=d_{1}-\sigma \sqrt{T-t}
\end{gathered}
$$

$N(x)$ is standard cumulative normal distributional function; $t$ is current time (Yeo \& Qiu, 2003). The model is based on the design of risk less hedge. By buying stock and simultaneous sale of call options for these stocks the investor creates risk less assets. Thus the profits from the sale of stock even out with losses from the buying of options and vice versa. The profitability of this kind of asset is equal to risk-free rate of return.

\section{Basics of Real Option Theory}

Success and applicability of the above described approach is the reason that in 1980 s methods for evaluating financial options were transferred to evaluating flexibility, in connection with investment (Dixit\& Pindyck, 1995)projects into physical assets, for example investment into technology, production systems and new product development. This type of option evaluation was named real options (Kogut\& Kulatilaka, 1994). Real options are options, bound to real assets and can be defined as the opportunity to react to changed project circumstances (Coff \& Laverty, 2002).

\begin{tabular}{|l|c|l|}
\hline \multicolumn{1}{|c|}{ Real options } & \multicolumn{1}{c|}{ Financial options } \\
\hline \multicolumn{1}{|c|}{ Investment opportunity } & Variable & \multicolumn{1}{c|}{ Call option } \\
\hline Current value of cash flows & $S$ & Current stock price \\
\hline Investment expenditure & $X$ & Exercise stock price \\
\hline $\begin{array}{l}\text { Possible time of decision to } \\
\text { defer }\end{array}$ & $T-t$ & Time to expiration date \\
\hline Time value of money & $R$ & Riskless return rate \\
\hline $\begin{array}{l}\text { Uncertainty of future cash } \\
\text { flows }\end{array}$ & $\sigma^{2}$ & $\begin{array}{l}\text { Variance of returns on } \\
\text { stock }\end{array}$ \\
\hline
\end{tabular}

Tab. 1. Comparison of investment opportunity and call option

Current value of created or purchased assets is equal to the stock price $(S)$ at the moment of option execution. The amount of used financial assets is equal to exercise price $(X)$. The time, that a company has available for postponement of appropriate investment decision, is equal to the time to expiration (T-t). Uncertainty (Miller\&Park, 2002), regarding future value of cash flows of the project is equal to 
standard variance of returns on stock. Time value of money is in both instances riskfree rate of return $(r)$.

On the basis of the above mentioned, the following can be summarised:

- Higher volatility of circumstances is therefore not reflected in greater losses, for they are limited with the original investment or investment in acquiring an option.

- Option offers practically unlimited possibilities to acquire benefits.

- Value of real option grows with available time interval, or time that is available for decision making.

As it can be seen, real options are based on the same principles as financial options. In spite of great similarity they are not completely the same. Among major differences are the following:

- Real options can be used with investments in tangible assets.

- Financial options have usually shorter life span, which is relatively simple to define.

- Financial options are connected to a kind of an underlying asset, that can be traded on various markets, therefore, this kind of asset cannot have negative value, which is not necessary the case with real options.

- Real options are usually more complex. Certain asset can include several options.

- Exercise prices in case of financial options are clearly defined, while they can, in the case of real options, randomly fluctuate though time.

- Value of real option and optimal time of execution of the option are dependent on the position of the company on the market.

The value of option comes from future behaviour of the underlying asset, for example the price of stock of the company, price of goods like oil (Bollen, 1999), or value of a project (for example a medicine that has not been developed fully). The first step in evaluating options is a prospect of movement of value of underlying asset in the future. The number of possible groups of asset value is enormous (Kremljak \& Buchmeister, 2006).

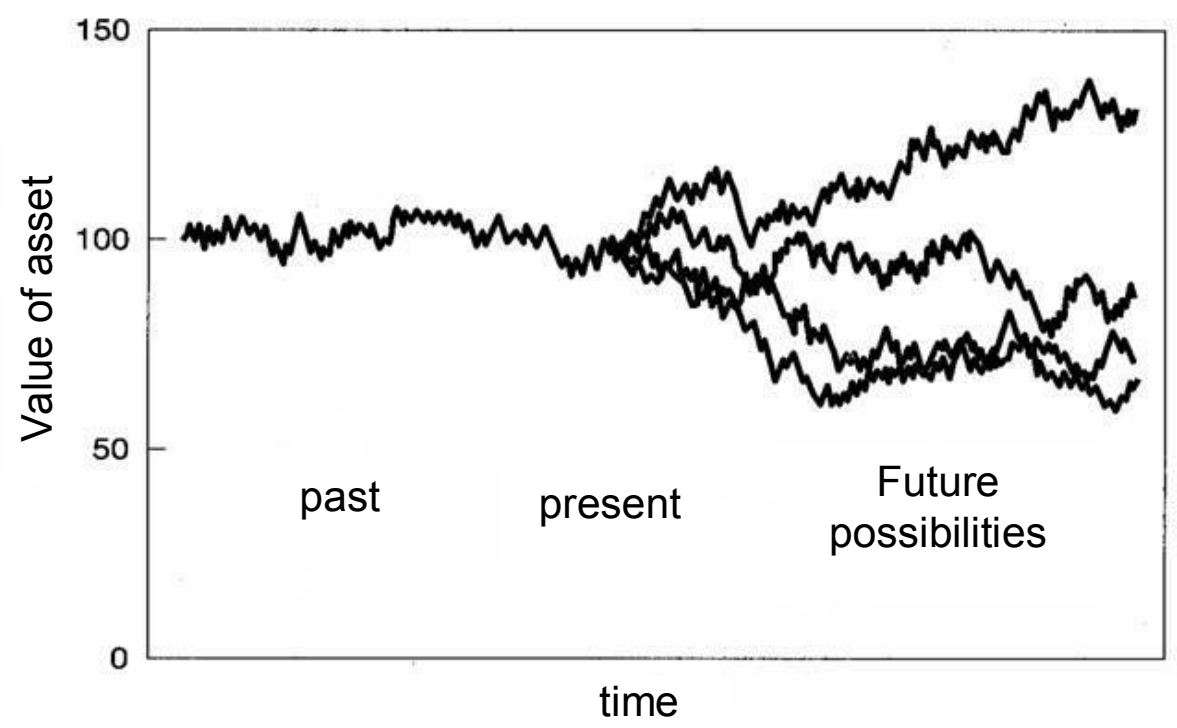

Fig. 3. Movement of value of asset in the future 
Figure 3 (Howell et al., 2001) shows the past path of asset value and only four possible future paths. These are designed by combining expected future trend (prices that grow on a certain level) and a coincidental element. The principle that stock price movement through time has characteristics of geometric Brown movement is one of the most important ones. If today we knew what the future movement of value of underlying asset will be, we could know in detail the optimal time to exercise the option, the value on the expiration date and thus also its current value. We could lose the meaning of options - the value which comes from uncertainty. Although we do not know which way the underlying asset value would travel we can imagine (and even more important, plan) a large number of possible future outcomes of asset value, where everyone results in different value of the option. If different option values, which come from possible ways, are appropriately combined, and if we also take into account their probabilities, current value of the option can be determined.

Basic model thus represents a coincidental walk which is a basis for many financial theories. It is also used for financial yield on company stock where there is a rule that "market has no memory". When there is only one variable (yield per stock), coincidental walk is described as 'one-dimensional'.

On the basis of the abovementioned data, one can see that defining the price variance of stock is one of the more important activities. Wrong definition quickly leads to overestimation of the option. For functional defining of volatility one of the following approaches can be chosen:

- Uses of historical data - past trends of price movements present an obvious way of defining volatility. Serious attention must be given to the quality of data and time of monitoring itself.

- Simulation of $x$ - Monte Carlo simulation can provide a useful tool for creating probability distribution of project returns.

- Reasonable price - volatility of $20-30 \%$ for an individual project is not excessively high. Individual projects have higher level of volatility then a diversified portfolio.

\section{Case}

Natural Resource Investments (Campbell, 2006)

Your company has a two year lease to extract copper from a deposit.

- Contains 7 million pounds of copper.

- 1-year development phase costs $\$ 1.2$ million immediately.

- Extraction costs of 85 cents per pound would be paid to a contractor in advance when production begins

- The rights to the copper would be sold at the spot price of copper one year from now.

- Percentage price changes for copper are $\mathrm{N}(0.07,0.20)$.

- The current spot price is 95 cents. 
- The discount rate for this kind of project (from the CAPM) is $10 \%$ and the risk less rate is $5 \%$.

Standard Expected NPV Analysis

$$
\begin{aligned}
& E[N P V]=-1.2+\frac{7\left(E\left[S_{1}\right]-0.85\right)}{1.1} \\
& E\left[S_{T}\right]=S_{0} e^{\mu T} \\
& E\left[S_{1}\right]=0.95 e^{0.07}=1.1089 \\
& E[N P V]=-1.2+\frac{7(1.0189-0.85)}{1.1}=-0.125
\end{aligned}
$$

Option Analysis

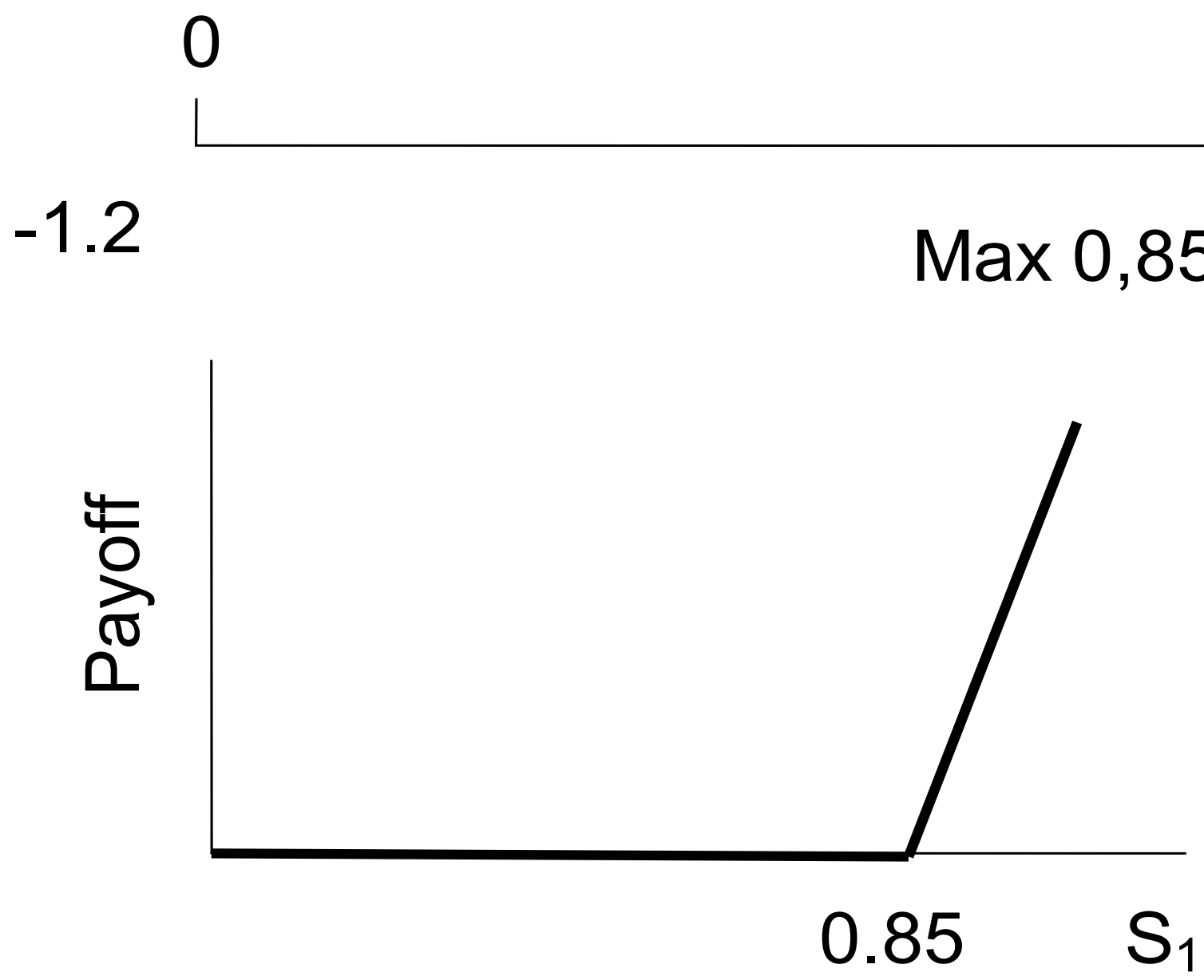

Fig. 4. Case of option analysis 


$$
\begin{aligned}
& C=S \mathrm{~N}\left(d_{1}\right)-X e^{-r T} \mathrm{~N}\left(d_{2}\right) \\
& d_{1}=\frac{\ln \left(\frac{S}{X}\right)+\left(r_{f}+0.5 \sigma^{2}\right) T}{\sigma \sqrt{T}} \\
& d_{1}=\frac{\ln \left(\frac{0.95}{0.85}\right)+\left(0.05+0.5(0.20)^{2}\right)}{0.20 \sqrt{1}}=0.906 \\
& d_{2}=d_{1}-\sigma \sqrt{T}=0.906-0.20=0.706 \\
& C=0.85 \mathrm{~N}(0.906)-0.85 e^{-0.05(1)} \mathrm{N}(0.706)=0.162
\end{aligned}
$$

\section{Distribution of Copper price at time 1}

Distribution of copper price (probability density) during the observed time period is shown in Figure 5.

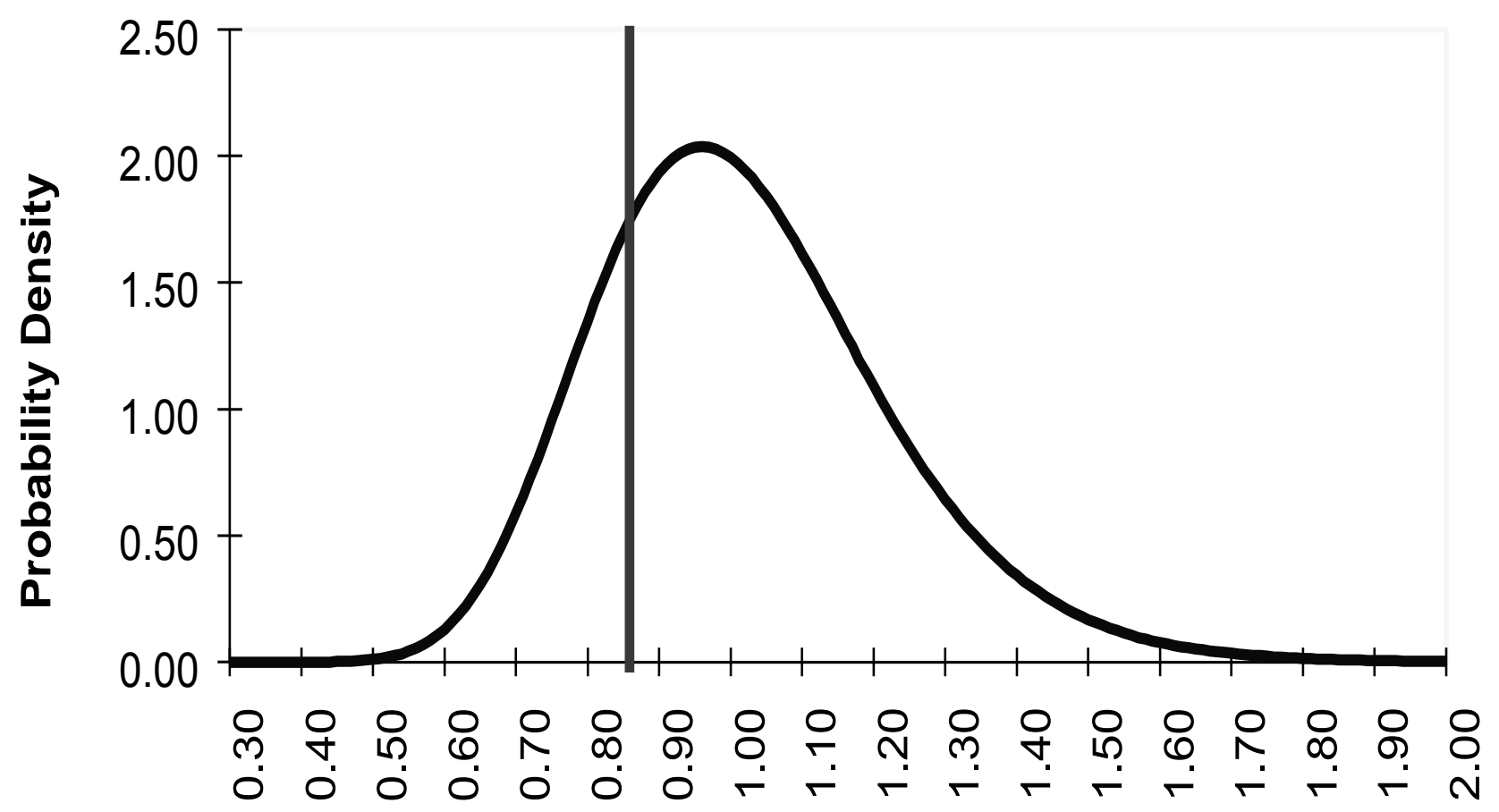

Copper Price

Fig. 5.Case of distribution 


\section{Shutdown and Restart Options}

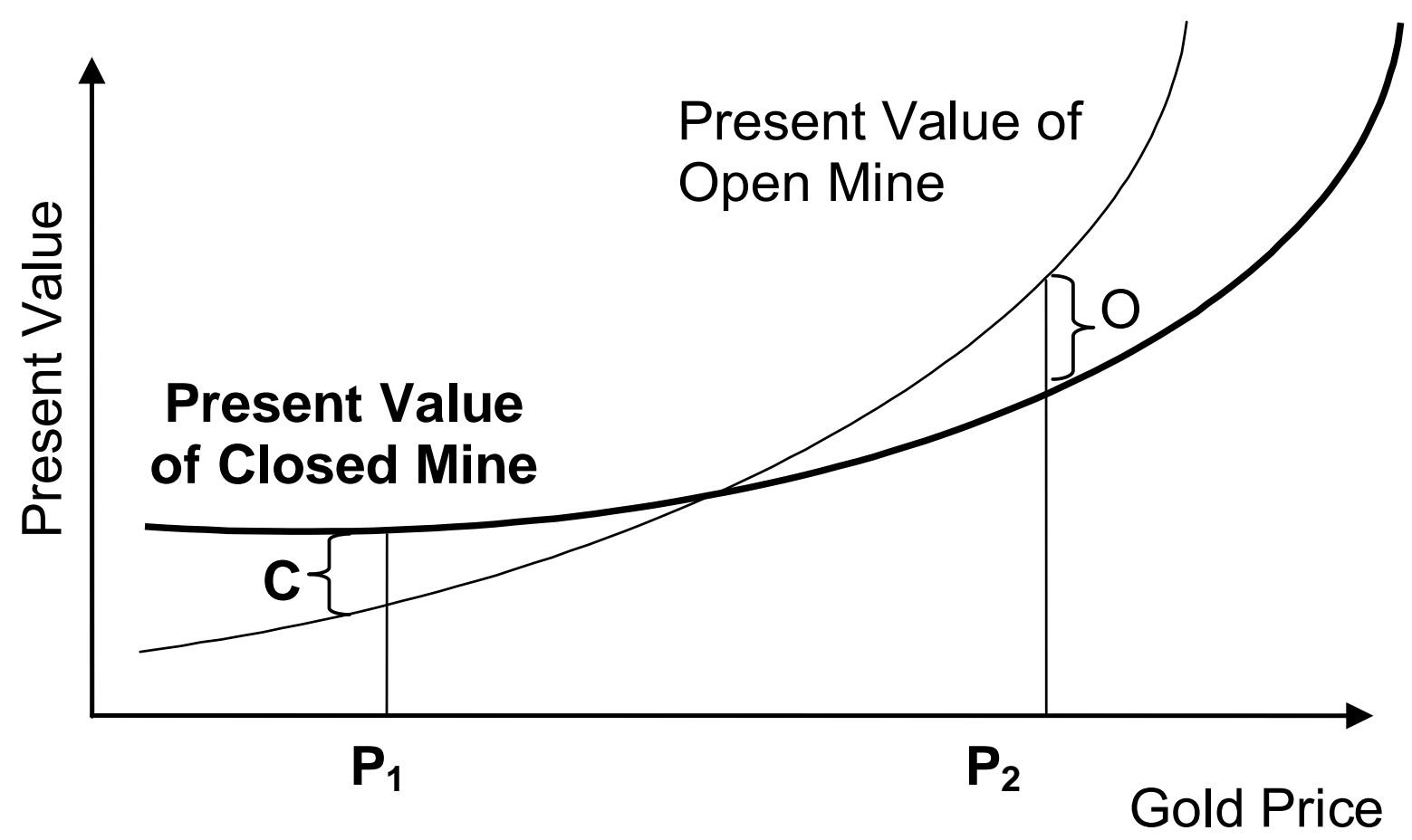

Fig.6. Shutdown and Restart Option of Mine

Decision Tree Analysis modifies the simple NPV-rule:

- The simple NPV rule gives generally not the correct conclusion if uncertainty can be "managed".

- The value of flexibility must be taken into account explicitly (cost of "killing an option").

- Properly calculated NPV remains the correct tool for decisions and evaluation of alternative strategies.

\section{Conclusion}

Scientific literature has shown that transfer of mathematical models from financial environment to the environment of isolated investment projects into production assets is successful. More problems arise when formal mathematical tools are used for complex developmental projects or strategic capability development. With strategic capability development it is almost impossible to precisely define the time left to expiry date. It is difficult to define volatility of an underlying asset. An underlying asset is actually knowledge developed in an organisation, but which is difficult to transform to money value which would be necessary for mathematical treatment. In spite of problems with the application of formal mathematical modelling, there is enough evidence in scientific literature that in capability development the mathematical models can be successfully substituted by the use of real options logic (Kogut \& Kulatilaka, 2001). Those who make decisions in organisational systems are advised to use real options logic. Its usefulness will not be 
increased by mathematical tools, which will reduce complex reality to a few variables, but by development of heuristics which will take into account the complexity of real conditions and at the same time enable decisions based on measurable indices.

Contribution of the article express usefulness of real options theory in the presented case as a tool to support a decision making process. It is shown when the investment in the mine of copper production should be closed or opened.

\section{References}

Bollen, N. (1999). Real options and product life cycles, Management Science, Vol. 45, No. 5, pp. 670-684

Campbell, R. H. (2006). Financial Global Management, Fuqua School of Business, Duke University, North Caroline

Coff, R. W. \& Laverty, K. J. (2002) Dilemmas in exercise decisions for real options on core competences, Working Paper

Dixit, A. \& Pindyck, R. S. (1995). The options approach to capital investment, Harvard Business Review, Vol. 73, No. 5-6, pp. 105-115

Howell, S.; Stark, A.; Newton, D.; Paxson, D.; Cavus, M.; Pereira, J. \& Patel, K. (2001). Real options: Evaluating corporate Investment Opportunities in a dynamic world, Pearson Education Limited, London

Kogut, B. \& Kulatilaka, N. (1994). Option thinking and platform investment: investing in opportunity, California Management Review, Vol. 36, No. 2, pp. $52-71$

Kogut, B. \& Kulatilaka, N. (2001). Capabilities as real options, Organization Science, Vol. 12, No. 6, pp. 744-758

Kremljak, Z.\& Buchmeister, B. (2006). Uncertainty and development of capabilities. DAAAM International Publishing Vienna

Miller, L. T. \& Park, C. S. (2002). Decision Making Under Uncertainty Real Options to the Rescue?, The Engineering Economist, Vol. 47, No. 2, pp. 105-149.

Trigeorgis, L. (2002). Real Options - Managerial Flexibility and Strategy in resourceAllocation, MIT Press, Cambridge

Yeo, K. T. \& Qiu, F. (2003) "The value of management flexibility - a real option approach to investment evaluation", International Journal of Project Management, Vol. 21, No. 4, pp. 243-250 